\title{
Osteosynthesis-screw augmentation by ultrasound-activated biopolymer - an ovine in vivo study assessing biocompatibility and bone-to-implant contact
}

Hanjo Neumann ${ }^{1 *}$, Stefan Breer ${ }^{1}$, Nils Reimers ${ }^{2}$, Richard Kasch ${ }^{3}$, Arndt-Peter Schulz ${ }^{2}$ and Benjamin Kienast ${ }^{1}$

\begin{abstract}
Objectives: Screw fixation and fragment anchoring in osteoporotic bones is often difficult. Problems like the cut out phenomenon and implant migration in osteoporotic bones have been reported. One possibility of improving the anchoring force of screws is augmentation of the screw. Cement-augmented screws in spinal surgery could exhibit a better anchoring in osteoporotic bones.
\end{abstract}

Methods: The purpose of this study was to examine the effect of screw augmentation using a resorbable polymer. Ultrasound-activated biodegradable pins were used for the purpose of a resorbable augmentation technique. Cannulated screws were inserted into the femur of 12 sheep and augmented by an ultrasound-activated polylactic acid (PLDLA) pin. In a paired approach, four screws were implanted in each animal: $2 \times$ a $10-\mathrm{mm}$ thread and $2 \times$ a $20-\mathrm{mm}$ thread, both of which were augmented with polymer. Both screws, named A and B, were also applied without augmentation (control group) and implanted into the contralateral hind limb. After 4, 8, and 12 weeks, the sheep were euthanized and a macroscopical and histological examination followed.

Results: The polymer spread well out of the screws into the cancellous lacunae. Around the polymer, the peripheral bone showed signs of healthy and active bone tissue. No evidence of inflammation or infection was observed. The boneto-implant contact was significantly higher in the augmented screws. Biocompatibility was proven in histopathological examination. After 12 weeks, no pathological changes were found.

Conclusion: Ultrasound-activated polymer augmentation of cannulated screws may improve the anchoring in osteoporotic bone.

\section{Article focus:}

- Can screw augmentation using a resorbable polymer improve the bone-to-implant contact in case of screw osteosynthesis?

- Is there any effect on the surrounding tissue by the induced temperature and liquefied polymer?

- Can biocompatibility be proven by this new osteosynthesis?

(Continued on next page)

\footnotetext{
* Correspondence: Hanjo_Neumann@gmx.de

'BG Trauma Hospital, Hamburg, Germany

Full list of author information is available at the end of the article
} 


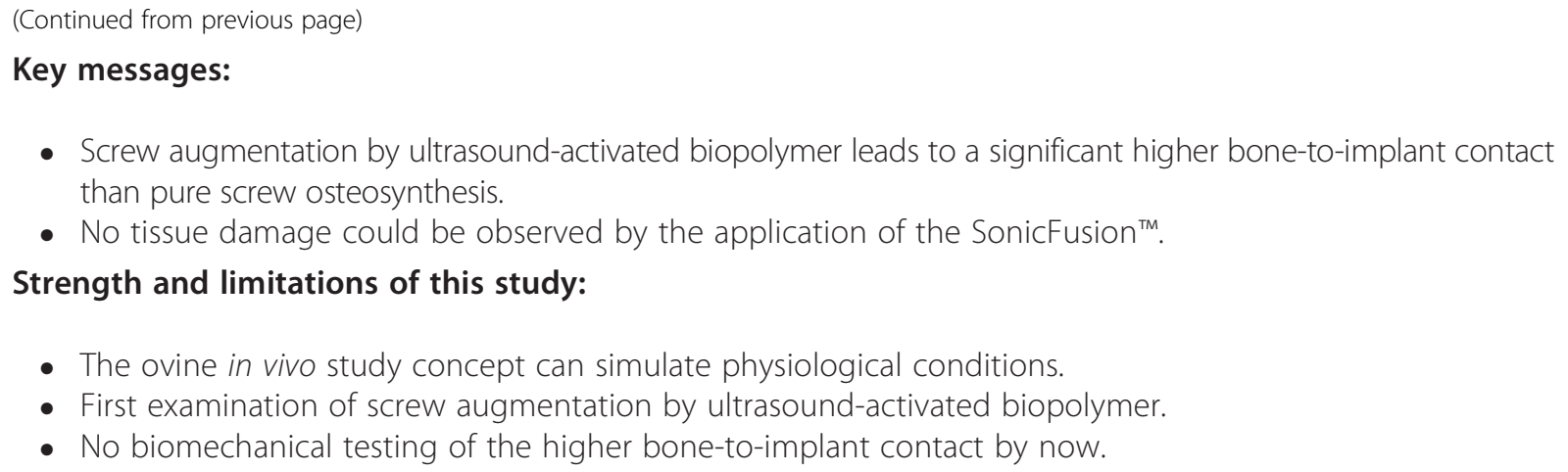

- The ovine in vivo study concept can simulate physiological conditions.

- First examination of screw augmentation by ultrasound-activated biopolymer.

- No biomechanical testing of the higher bone-to-implant contact by now.

Keywords: Biocompatibility, Ultrasound-activated polymer, Augmented screw, Ovine in vivo study

\section{Introduction}

The number of osteoporotic fractures has risen dramatically in the last two decades and demographic data shows a further increase of these injuries [1,2]. Screw fixation and fragment anchoring in osteoporotic bones can be extremely difficult [3-5]. Problems like the cut out phenomenon and implant migration in osteoporotic bones with the need of revision operations have been reported $[3,6]$.

Therefore, many different solutions are currently under investigation. The design of the osteosynthesis screw has changed from a round profile to a blade design to prevent a migration of the implant in the osteoporotic bone [7]. Another approach to a stronger fixation of screws in osteoporotic bones is the preparation of the implant surface with bioactive substances. In a study with rats, Zoledronate-coated screws exhibit a higher bone density around the implant [8]. Calcium pyrophosphate-coated titanium screws exhibited a significantly higher toque when removing the screw after healing compared to uncoated screws [9].

Another idea for improving the anchoring force of screws is the augmentation of the screw itself $[10,11]$. Over the past years, augmentation of screws with bone cement (poly(methylmethacrylate) (PMMA)) was intensively investigated in the area of spinal surgery. The pullout force of screws in the pedicle proved to be higher with PMMA cement augmentation [12,13]. Newer studies showed similar pullout forces using calcium phosphate cement [14]. In comparison to PMMA cement, the solidification of calcium phosphate cement is non-exothermic with a lower potential for thermal necrosis of the adjacent tissue, and most importantly, it is bioresorbable [15]. In vivo studies and biomechanical studies report a leakage rate of $30 \%-$ $50 \%[16,17]$. A typical problem in the osteoporotic bone of the typical elderly patient is the cut out phenomenon, when intramedullary osteosynthesis devices can perforate the cortex of the bone and lead to complications [18].
Cement augmentation of an intramedullary osteosynthesis in laboratory analysis was able to prove an enhanced pullout resistance and a stronger rotational stability $[10,19,20]$. Clinical experience in cement-augmented osteosynthesis for femoral neck fractures showed promising results $[21,22]$.

The aim of this study was to examine screw augmentation with an absorbable polymer. In recent times, ultrasound-activated biodegradable pins have been tested for the purpose of being used for resorbable osteosynthesis [23-27]. The biocompatibility and safety of these (nonactivated) co-polymers has been demonstrated in several studies $[28,29]$. The examination of ultrasound-activated pins showed no specific tissue damage caused by the induced heat of the melting process. There was rather evidence of an enhanced bone/implant contact [23].

During the study, the in vivo biocompatibility and performance of the so-called "SonicFusion" ${ }^{\text {Ts" }}$ inside-out technology was tested using a sheep model. Therefore, cannulated screws were augmented by an inserted, ultrasound-activated polylactic acid (PLDLA) pin, which can melt through perforations in the screw into the surrounding tissue. This study shall prove a higher boneto-implant contact (BIC) of a screw osteosynthesis by augmentation of the screw with an ultrasound-activated PLDLA pin and shall show that the melting process causes no further damage to the surrounding tissue.

\section{Material and methods}

\section{Animals}

Twelve female sheep (Ovis aries), at least 2 years of age (adult animals), were used for this examination. At time of surgery, their mean weight was $59.3 \mathrm{~kg}$. The acclimation period was 5 days; $24 \mathrm{~h}$ before surgery, the animals started fasting.

This study was conducted in accordance with the requirements of the FDA Good Laboratory Practice (GLP) regulations, 21 CFR 58 (revision of 1 April 2007) and the 


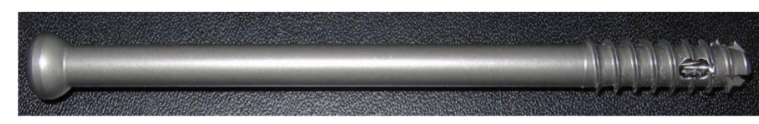

Figure 1 Cannulated inside-out screw with flow geometry in thread.

OECD Good Laboratory Practice, reference ENV/CM/ CHEM (98)11 adopted by the council on 26 November 1997.

\section{Implants}

The test articles were modified Asnis screws (Stryker $\mathrm{GmbH}$, Schönkirchen, Germany), $6.5 \mathrm{~mm}$ in diameter, with a length of $60 \mathrm{~mm}$. Modification of these titanium screws included additional holes on the side of the thread of each screw to allow the melted polymer to spread out (Figure 1). Test article A represented a thread of $10-\mathrm{mm}$ length and test article B a thread of 20-mm length.

For augmentation, an inside-out (poly-L-lactide) PLDLA was used. The PLDLA pin consists of a polymer of poly (L-lactide-co-D,L-lactide) at a ratio of 70:30. Using ultrasonic energy, the fusion process binds a resorbable thermoplastic polymer device to the bone. The applied energy had a frequency of $20 \mathrm{kHz}$, an amplitude of $20 \mu \mathrm{m}$, and a power of $10 \mathrm{~W}$ and was applied by a specific ultrasound applicator to the top of the pin. The ultrasonic signal of high frequency and low amplitude is applied resulting in a local melting of the pin tip. Tissue damage because of the heat impact could not be found [23,30]. The liquefied polymer flows out of the perforation in the screw and fills the lacunae of the cancellous bone (Figure 2). Immediately after stopping the use of ultrasound, the material solidifies and hardens, providing a three-dimensional anchoring.

\section{Surgery}

The animals were operated under a combined anesthesia which included barbiturates and atropine. Each animal received analgesia preoperatively and also a prophylactic infusion of penicillin. After disinfection, an incision after disinfection on the medial side of the femur, proximal and partly over the knee joint, was made. The muscles were separated, and the implantation site was cleared. The two implants on each operation site were spaced $12 \mathrm{~mm}$ apart. A K-wire (3. $2 \mathrm{~mm}$ in diameter) was placed perpendicular to the bone axis. Drilling was conducted using a cannulated drill of 4.9-mm diameter, followed by rinsing with saline to remove debris. For the actual augmentation process, polymer was placed into the screw before implantation, and the screw was manually inserted into the drilling hole. After putting the ultrasound device on the polymer, activation of the ultrasound device led to a melting of the polymer, which was inserted under constant pressure. The contralateral screws were not augmented (control group). Afterwards, the incision was closed by suture, and the operated legs were not restrained. After surgery, a mediolateral radiograph was taken.

Three time periods for observation were chosen $(n=4$ sites per group and time period): 4 weeks (4 animals), 8 weeks ( 4 animals), and 12 weeks ( 4 animals). In a paired approach, four test articles were implanted in each animal (Table 1): A (thread of 10-mm length) and B (thread of $20-\mathrm{mm}$ length), both augmented with polymer; the contralateral hind limb was used for both screws A and B, applied without augmentation (control group).

Upon termination, the implant sites were macroscopically inspected and graded for inflammation. The histological comparison of the implantation sites was used to examine the biocompatibility of the SonicFusion ${ }^{\mathrm{nt}}$ inside-out technology.

\section{Scoring}

At the appropriate termination interval, after sedation, the designated animals were euthanized with a lethal injection of barbiturates.

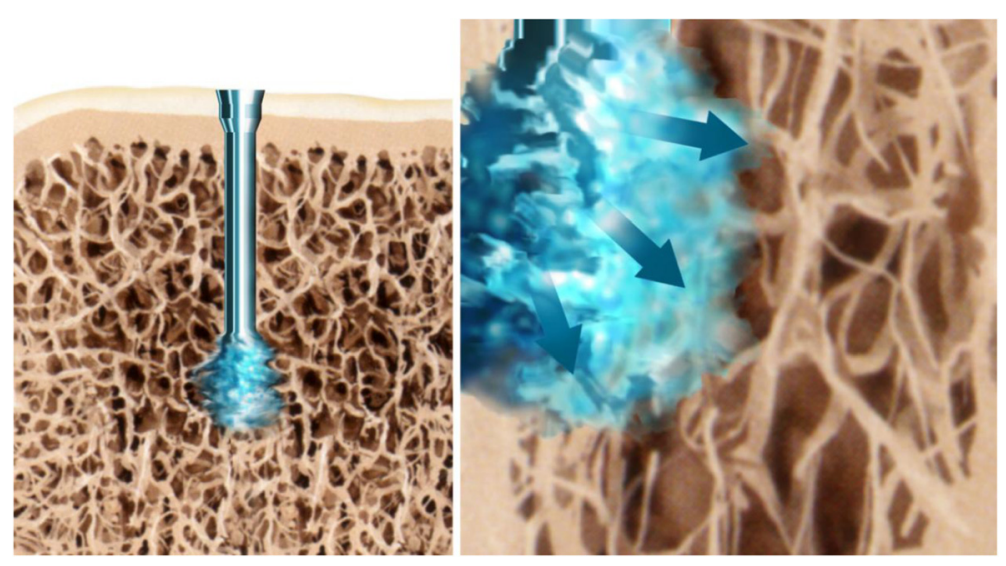

Figure 2 Schematic view on the mode of operation of the melting in a SonicPin ${ }^{\mathrm{Tm}}$ osteosynthesis. 
Table 1 Study design

\begin{tabular}{lllll}
\hline & & \multicolumn{2}{l}{ Time period } \\
\cline { 2 - 5 } Test article & Process & $\mathbf{4}$ weeks & $\mathbf{8}$ weeks & 12 weeks \\
\hline Test article A, test & Augmented & 4 & 4 & 4 \\
$\begin{array}{l}\text { Test article A, } \\
\text { control }\end{array}$ & Non-augmented & 4 & 4 & 4 \\
Test article B, test & Augmented & 4 & 4 & 4 \\
$\begin{array}{l}\text { Test article B, } \\
\text { control }\end{array}$ & Non-augmented & 4 & 4 & 4 \\
Total number of & & 16 screws & 16 screws & 16 screws \\
sites & & & & \\
\hline
\end{tabular}

The implant sites were inspected and graded for inflammation macroscopically. The color and consistency of the tissue at the implanted sites was observed and recorded using a semi-quantitative scoring system (Table 2).

For histological analysis, the femora were harvested and samples of the implant sites and surrounding bony tissue were collected and fixed in $10 \%$ neutral formalin. The samples were dehydrated in alcoholic solutions with increasing concentrations, cleared in xylene, and embedded in resin. The embedded samples were cut along the longitudinal axis of the implant and stained with modified paragon. A semi-quantitative evaluation of the local tolerance was performed in compliance with ISO 10993-6, which included the evaluation of fibrin, necrosis, tissue degeneration, signs of infection, inflammatory reaction (polymorphonuclear cells, eosinophilic polymorphonuclear cells, lymphocytes, plasma cells, macrophages, giant cells), fibrocytes, fibroconnective tissue, and neovascularization. Particular attention was paid to the thermal effects of the augmentation procedure on the surrounding tissue. The performance of the augmented/non-augmented processes was assessed qualitatively and semi-quantitatively assessed by analyzing osseointegration and bone neoformation, osteoblasts and osteoclasts, fibrous tissue, bone remodeling, signs of infection, and material degradation.

The BIC was examined in a blinded manner by digitalizing and examining the slides with Zeiss Axio Scope microscope (Carl Zeiss microscopy GmbH, Jena, Germany)

Table 2 Semi-quantitative scoring system for macroscopic inflammation reaction

\begin{tabular}{ll}
\hline Reaction & Grade \\
\hline None & 0 \\
Light & 1 \\
Moderate & 2 \\
Marked & 3 \\
Severe & 4 \\
\hline
\end{tabular}

equipped with a color image-analysis system. The surface of the implant (screw or polymer) and the surrounding tissue was measured quantitatively in percent (Figures 3 and 4).

\section{Statistical analysis}

Statistical analysis of the histomorphometrical data were performed using a Mann-Whitney test (SPSS version 15.0, USA).

\section{Results}

\section{Macroscopic scoring}

All screws (augmented and non-augmented) could be implanted without technical complications.

The macroscopic approach showed slight-to-moderate signs of edemas in the 4-week group. The 8- and 12week group did not exhibit any noticeable problems (mean points in semi-quantitative macroscopical scoring 1.75 vs. 0.0 vs. 0.25 , (acc. Table 2)). There were no signs for infection or inflammation in any group. Significant differences were not found by macroscopic scoring.

\section{Histological scoring}

In the 4-week group, the non-augmented screws ( $A$ and $B$ ) showed a good level of osseointegration, despite occasional interpositional fibrous tissue. The non-augmented screw $B$ was slightly better osteointegratedthan screw $A$. Observation of the augmented screws showed a similar polymer spread through the neighboring bone lacunae in both screws. In both augmented screws, the polymer or associated thermal effects resulted, in evidence of non-living and living bone embedded within the polymer, with slight signs of focal bone marrow fibrosis and absence of necrosis and bone absorption. Around the polymer, the peripheral bone showed signs of healthy and active bone tissue. The augmented screw $B$ was slightly better osseointegrated than augmented screw $A$. No evidence of inflammation or infection could be observed.

In the 8-week group, the non-augmented screws ( $A$ and $B$ ) showed a good level of osseointegration, despite occasional interpositional fibrous tissue. After 8 weeks, both of the non-augmented screws showed a similar osseointegration. Slight bone ingrowth into the lateral screw perforations could be observed. In both augmented screws, the polymer spread into the surrounding lacunae of the bone. In comparison to the 4-week group, fewer inflammatory cell and less osteoblast activity could be found. In screw group $\mathrm{A}$, the bony trabeculae embedded within the polymer showed discreet signs of atrophy. Around the polymer, the peripheral bone showed signs of healthy and active bone tissue. No significant evidence of inflammation or infection could be observed. Polymer degradation was not found after 8 weeks. Augmented screw $B$ was slightly better osseointegrated than augmented screw $A$. 


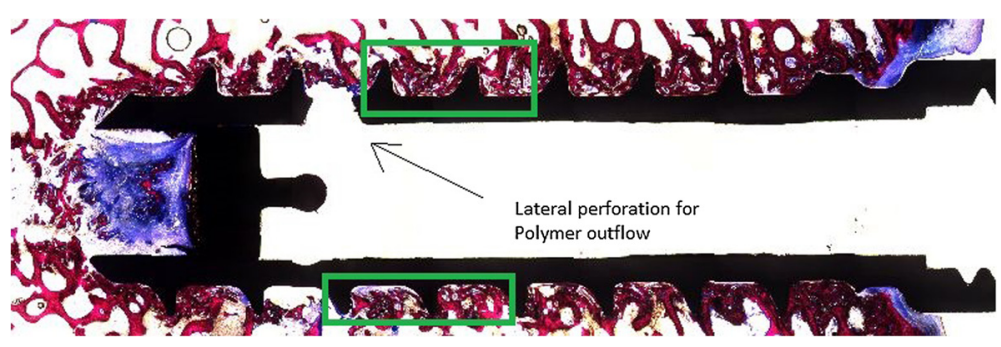

Figure 3 Histological view of augmented screw (test article B).

In the 12-week group, the non-augmented screw $A$ showed slight-to-moderate signs of peripheral inflammatory reactions (fibrin, macrophages, osteoclasts), while the non-augmented screw $B$ exhibited a better osseointegration without significant pathological changes. In both augmented screws, the polymer spread into the surrounding lacunes of the bone. After 12 weeks, the augmented screws showed less inflammatory reaction than after 4 or 8 weeks. Good osseointegration with some interfacial fibrous reactions could be observed.

The thermal effect on the bone marrow was no longer visible. Living and non-living osteocytes embedded in the polymer could be observed as well. Around the polymer, the peripheral bone showed signs of healthy and active bone tissue. No evidence of inflammation or infection could be observed. After 12 weeks, there were no signs of a polymer degradation. The augmented screw $B$ was slightly better osteointegrated than augmented screw $A$.

\section{Bone-to-implant contact (BIC)}

At no point in time were there any statistical differences in the non-augmented group. In the augmented group, there were no significant differences in the BIC of the screw itself and the surrounding tissue. The analysis of the BIC with the polymer showed significant differences in the 4- and 8-week group concerning the comparison of screw A and B ( $p=0.021$ and 0.019 , respectively). The comparison in the 12-week group of screws A and B with regard to the BIC with the polymer was not significantly different (Table 3).

\section{Discussion}

All screws as well as the augmentation could be applied safely. The macroscopical analysis showed a slight edema in the 4-week group, due to surgical trauma. There were no signs of infection or inflammation in any groups.

At all healing intervals, whether with or without augmentation, histopathological analysis showed that screw B (thread of 20-mm length) was slightly better osseointegrated than screw A (thread of 10-mm length), due to higher contact area because of the longer tread.

The non-augmented screws were considered as locally tolerated as well. The desired effect of polymer flowing out of the screw was confirmed in all cases of augmented screws. The extruded polymer was always in accordance with the polymer located in the screws. If bony tissue was completely embedded in and surrounded by polymer, rare non-living osteocytes and a slight bone marrow fibrosis could be observed. After a healing time of 12 weeks, however, complete healing and renewal of the adjacent medullar tissue was observed. No significant signs of necrosis, bone resorption, or biodegradation could be seen around the polymer.

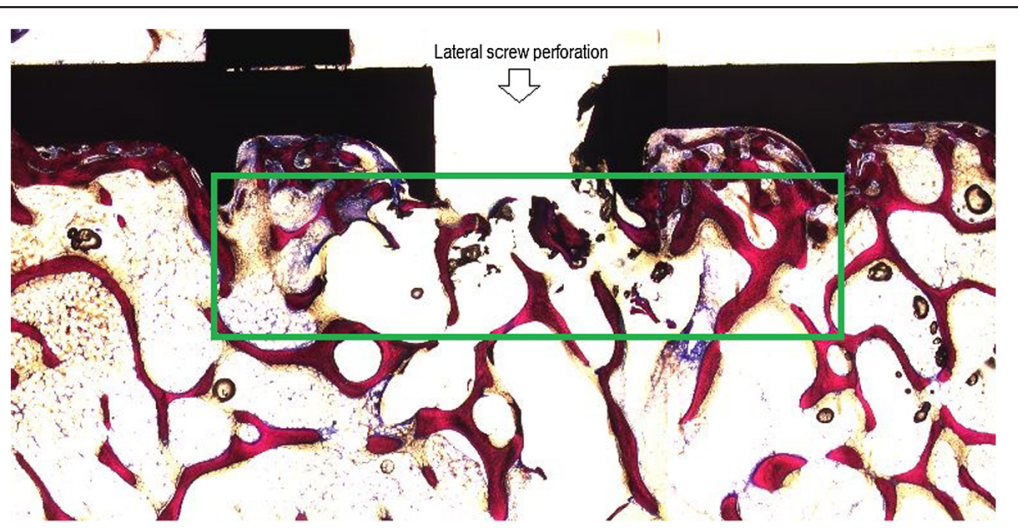

Figure 4 Histological view of augmented screw (test article B) next to lateral perforation for polymer. 
Table 3 Bone-to-implant contact (BIC) in percent

\begin{tabular}{llll}
\hline Time period & $\begin{array}{l}\text { BIC with screw material } \\
\text { (non-augmented) (\%) }\end{array}$ & $\begin{array}{l}\text { BIC with screw material } \\
\text { (augmented) (\%) }\end{array}$ & $\begin{array}{l}\text { BIC with polymer material } \\
\text { (augmented) (\%) }\end{array}$ \\
\hline 4 weeks & B: 18.5 & B: 17.8 & B: 21.8 \\
& A: 11.9 & A: 9.6 & A: 55.2 (significant) \\
8 weeks & B: 20.5 & B: 17.7 & B: 42.2 \\
& A: 23.9 & A: 17.3 & A: 74.5 (significant) \\
12 weeks & B: 30.2 & B: 42.3 & B: 65.8 \\
& A: 19.8 & A: 39.0 & A: 58.9 \\
\hline
\end{tabular}

All in all, the osteointegration of screw B (thread of $20 \mathrm{~mm}$ ) exhibited overall the best results. The overall anchoring potential of the augmented screws outperformed that of the non-augmented screws, and the limited local thermal effect of the melting process was not significantly detrimental to the adjacent and limited portion of bone tissue involved.

The analysis of the BIC was uncertain due to the difficulties of being able to clearly identify the limits between the living and non-living bone in contact with the polymer. The BIC of the screw itself with the bony tissue showed no significant differences. But as seen in Table 2, the $\mathrm{BIC}$ of the polymer with the surrounding bone is significantly higher than the $\mathrm{BIC}$ with the bare screw to the bone $(p=0.038)$. Furthermore, the comparison of the augmented screws A and B to each other showed significant differences in the 4- and 8-week groups.

In their study, dealing with cement augmentation in pedicle screws, Sarzier et al. could show that the more osteoporotic the bone, the more significantly different is the anchoring of the screws [23,31]. A good bone-toimplant contact led to higher pullout forces. Paech et al. could prove in a biomechanical laboratory test that polymer-augmented lag screws in the treatment of femoral neck fractures exhibited a better protection against a cut out failure in osteoporotic bones [32]. The augmented screws exhibit a particular advantage in the cases of osteoporotic bones and can therefore also improve the stability of a screw osteosynthesis in these cases.

Kock et al. reported about an in vitro study of a polymeraugmented screw fixation with good pullout and torque forces, when a conventional screw is applied in a drilling hole, that was filled with a new resorbable polymer (on the basis of alkylene bis(oligolactoyl)methacrylates) beforehand [33]. Whether this testing scenario can be implemented in clinical practice is yet to be shown.

Concerning the BIC, Huang et al. could demonstrate in a laboratory study that a higher BIC is significantly correlated to a higher primary stability [34]. For the animal trial, a higher primary stability of augmented screws can be postulated if a higher BIC can be observed as was the case in our study. Mechanical tests have yet to follow before clinical test can be performed.

\section{Conclusion}

Screw augmentation by resorbable, ultrasound-activated polymers is safe and biocompatible. No thermal effects on the adjacent bone were observed, while the bone-toimplant contact can be increased by this technique. In cases of osteoporotic fractures, this technique might provide a higher anchoring potential with a resorbable material.

\section{Competing interests}

The authors declare that they have no competing interests.

\section{Authors' contributions}

$\mathrm{HN}$ and BK made substantial contributions to the conception, execution, and design of the study and performed the animal trial. SB assisted performing the animal trials. RK gave his substantial contribution in histopathological analysis. APS contributed substantially to data interpretation and manuscript revision. NR was involved in manuscript revision and data analysis. All authors read and approved the final manuscript.

\section{Acknowledgement}

The University of Schleswig-Holstein, Campus Lübeck, Germany was partially funded by the Stryker Trauma GmbH, Schönkirchen, Germany.

\section{Author details}

${ }^{1}$ BG Trauma Hospital, Hamburg, Germany. ${ }^{2}$ Medical Faculty, University of Lübeck, Lübeck, Germany. ${ }^{3}$ Department of Orthopaedics, University

Greifswald, Greifswald, Germany.

Received: 19 November 2014 Accepted: 4 January 2015

Published online: 28 January 2015

References

1. Kannus P, Parkkari J, Koskinen S, Niemi S, Palvanen M, Jarvinen M, et al. Fallinduced injuries and deaths among older adults. JAMA. 1999;281(20):1895-9.

2. Jones G, Nguyen T, Sambrook PN, Kelly PJ, Gilbert C, Eisman JA. Symptomatic fracture incidence in elderly men and women: the Dubbo Osteoporosis Epidemiology Study (DOES). Osteoporos Int. 1994;4(5):277-82

3. Barrios C, Brostrom LA, Stark A, Walheim G. Healing complications after internal fixation of trochanteric hip fractures: the prognostic value of osteoporosis. J Orthop Trauma. 1993;7(5):438-42

4. Schulz AP, Reimers N, Wipf F, Vallotton M, Bonaretti S, Kozic N, et al. Evidence based development of a novel lateral fibula plate (VariAx Fibula) using a real $C T$ bone data based optimization process during device development. Open Orthop J. 2012;6:1-7.

5. Voigt C, Geisler A, Hepp P, Schulz AP, Lill H. Are polyaxially locked screws advantageous in the plate osteosynthesis of proximal humeral fractures in the elderly? A prospective randomized clinical observational study. J Orthop Trauma. 2011;25(10):596-602.

6. Davis TR, Sher JL, Horsman A, Simpson M, Porter BB, Checketts RG. Intertrochanteric femoral fractures. Mechanical failure after internal fixation. J Bone Joint Surg Br. 1990;72(1):26-31.

7. Lenich A, Vester H, Nerlich M, Mayr E, Stockle U, Fuchtmeier B. Clinical comparison of the second and third generation of intramedullary devices for trochanteric fractures of the hip-Blade vs screw. Injury. 2010;41(12):1292-6. 
8. Andersson T, Agholme F, Aspenberg P, Tengvall P. Surface immobilized zoledronate improves screw fixation in rat bone: a new method for the coating of metal implants. J Mater Sci Mater Med. 2010;21(11):3029-37.

9. Lee $\mathrm{JH}, \mathrm{Nam} \mathrm{H}$, Ryu HS, Seo JH, Chang BS, Lee CK. Bioactive ceramic coating of cancellous screws improves the osseointegration in the cancellous bone. J Orthop Sci. 2011;16(3):291-7.

10. Schulz AP, Seide K, Queitsch C, von Haugwitz A, Meiners J, Kienast B. Results of total hip replacement using the Robodoc surgical assistant system: clinical outcome and evaluation of complications for 97 procedures. Int $J$ Med Robot. 2007;3(4):301-6.

11. Larsson S, Stadelmann VA, Arnoldi J, Behrens M, Hess B, Procter P. Injectable calcium phosphate cement for augmentation around cancellous bone screws. In vivo biomechanical studies. J Biomechanics. 2012;45(7):1156-60.

12. Burval DJ, McLain RF, Milks R, Inceoglu S. Primary pedicle screw augmentation in osteoporotic lumbar vertebrae: biomechanical analysis of pedicle fixation strength. Spine (Phila Pa 1976). 2007;32(10):1077-83.

13. Cook SD, Salkeld SL, Stanley T, Faciane A, Miller SD. Biomechanical study of pedicle screw fixation in severely osteoporotic bone. Spine J. 2004;4(4):402-8.

14. Yazu M, Kin A, Kosaka R, Kinoshita M, Abe M. Efficacy of novel-concept pedicle screw fixation augmented with calcium phosphate cement in the osteoporotic spine. J Orthop Sci. 2005;10(1):56-61.

15. Constantz BR, Ison IC, Fulmer MT, Poser RD, Smith ST, VanWagoner M, et al. Skeletal repair by in situ formation of the mineral phase of bone. Science. 1995;267(5205):1796-9.

16. Frankel BM, Jones T, Wang C. Segmental polymethylmethacrylateaugmented pedicle screw fixation in patients with bone softening caused by osteoporosis and metastatic tumor involvement: a clinical evaluation. Neurosurgery. 2007;61(3):531-7. discussion 537-8.

17. Bullmann V, Schmoelz W, Richter M, Grathwohl C, Schulte TL. Revision of cannulated and perforated cement-augmented pedicle screws: a biomechanical study in human cadavers. Spine (Phila Pa 1976). 2010;35(19):E932-9.

18. Alho A, Benterud JG, Solovieva S. Internally fixed femoral neck fractures. Early prediction of failure in 203 elderly patients with displaced fractures. Acta Orthop Scand. 1999;70(2):141-4.

19. Erhart S, Schmoelz W, Blauth M, Lenich A. Biomechanical effect of bone cement augmentation on rotational stability and pull-out strength of the Proximal Femur Nail Antirotation. Injury. 2011;42(11):1322-7.

20. Moore DC, Frankenburg EP, Goulet JA, Goldstein SA. Hip screw augmentation with an in situ-setting calcium phosphate cement: an in vitro biomechanical analysis. J Orthop Trauma. 1997;11(8):577-83.

21. Dall'Oca C, Maluta T, Moscolo A, Lavini F, Bartolozzi P. Cement augmentation of intertrochanteric fractures stabilised with intramedullary nailing. Injury. 2010;41(11):1150-5.

22. Wu MH, Lee PC, Peng KT, Wu CC, Huang TJ, Hsu RW. Complications of cement-augmented dynamic hip screws in unstable type intertrochanteric fractures - a case series study. Chang Gung Med J. 2012;35(4):345-53.

23. Arnoldi J, Henry $P$, Procter $P$, Robioneck $B$, Jonsson A. In vivo tissue response to ultrasound assisted application of biodegradable pins into cortical and cancellous bone structures: a histological and densitometric analysis in rabbits. J Biomater Sci Polym Ed. 2012;23(5):663-76.

24. Schneider M, Seinige C, Pilling E, Rasse M, Loukota R, Stadlinger B. Ultrasound-aided resorbable osteosynthesis of fractures of the mandibular condylar base: an experimental study in sheep. Br J Oral Maxillofac Surg. 2011;50(6):528-32.

25. Schneider M, Eckelt U, Reitemeier B, Meissner H, Richter G, Loukota R, et al. Stability of fixation of diacapitular fractures of the mandibular condylar process by ultrasound-aided resorbable pins (SonicWeld RxÆ System) in pigs. Br J Oral Maxillofac Surg. 2011;49(20627494):297-301.

26. Nkenke E, Vairaktaris E, Schwarz S, Eyupoglu I, Ganslandt O, Leis T, et al. Prospective assessment of complications associated with ultrasound activated resorbable pin osteosynthesis in pediatric craniofacial surgery: preliminary results. Neurocirugia. 2011;22(6):498-506.

27. Reichwein A, Schicho K, Moser D, Seemann R, Poeschl P, Baumann A, et al. Clinical experiences with resorbable ultrasonic-guided, angle-stable osteosynthesis in the panfacial region. J Oral Maxillofac Surg. 2009;67(6):1211-7.

28. Ignatius $\mathrm{AA}$, Claes LE. In vitro biocompatibility of bioresorbable polymers: poly $(\mathrm{L}, \mathrm{DL}$-lactide) and poly(L-lactide-co-glycolide). Biomaterials. 1996;17(8):831-9.

29. Prokop A, Jubel A, Helling HJ, Eibach T, Peters C, Baldus SE, et al. Soft tissue reactions of different biodegradable polylactide implants. Biomaterials. 2004;25(2):259-67.
30. Neumann H, Schulz AP, Gille J, Klinger M, Jurgens C, Reimers N, et al. Refixation of osteochondral fractures by ultrasound-activated, resorbable pins: An ovine in vivo study. Bone Joint Res. 2013;2(2):26-32.

31. Sarzier JS, Evans AJ, Cahill DW. Increased pedicle screw pullout strength with vertebroplasty augmentation in osteoporotic spines. J Neurosurg. 2002;96(3 Suppl):309-12.

32. Paech A, Wilde E, Schulz AP, Heinrichs G, Wendlandt R, Queitsch C, et al. Biopolymer augmentation of the lag screw in the treatment of femoral neck fractures-a biomechanical in-vitro study. Eur J Med Res. 2010;15(4):174-9.

33. Kock H-J, Pokinskyj P, Wenz R, Linhart W. Screw fixation in cancellous osteoporotic bone - first in vitro results with a novel augmentation material Eur J Trauma. 2001;27(5):250-6.

34. Huang HL, Tsai MT, Su KC, Li YF, Hsu JT, Chang CH, et al. Relation between initial implant stability quotient and bone-implant contact percentage: an in vitro model study. Oral Surg Oral Med Oral Pathol Oral Radiol. 2012;116(5):e356-61.

\section{Submit your next manuscript to BioMed Central and take full advantage of:}

- Convenient online submission

- Thorough peer review

- No space constraints or color figure charges

- Immediate publication on acceptance

- Inclusion in PubMed, CAS, Scopus and Google Scholar

- Research which is freely available for redistribution 